\title{
The concept of control in chronic obstructive pulmonary disease: Development of the criteria and validation for use in clinical practice
}

\author{
M.Miravitlles ${ }^{1}$, B.Alcázar ${ }^{2}$, J.J.Soler-Cataluña ${ }^{3}$
}

1 - Pneumology Department, Vall d'Hebron Hospital Universitari / Vall d'Hebron Institut de Recerca (VHIR), Vall d'Hebron Barcelona Hospital Campus:

P. Vall d'Hebron 119-129, 08035, Barcelona, Spain;

2 - Respiratory Department, Hospital de Alta Resolución de Loja: Avenida Tierno Galvan s/n, 18300, Loja, Spain;

3 - Pneumology Department, Hospital Arnau de Vilanova: Carrer de Sant Clement 12, 46015, Valencia, Spain

Author information

Miravitlles Marc, Consultant pulmonologist, Pneumology Department, Hospital Universitari Vall d'Hebron, tel. / fax: (34) 932-746-083; e-mail: marcm@separ.es Alcázar Bernardino, Consultant pulmonologist Respiratory Department, Hospital de Alta Resolución de Loja; tel.: (34) 958-338-150; e-mail: balcazarnavarrete @gmail.com

Soler-Cataluña Juan José, Head of Department, Pneumology Department, Hospital Arnau de Vilanova; tel.: (34) 961-976-000; e-mail: jjsoler@telefonica.net

\begin{abstract}
Guidelines of treatment of chronic obstructive pulmonary disease (COPD) identify symptom reduction and prevention of exacerbations as the main goals of therapy. Initial pharmacological treatment must be guided by these parameters, and effectiveness must be assessed at each clinical visit. However, there is no clear guidance as to how this assessment must be performed. The concept of control has been well developed in asthma, but it has been elusive in COPD. Patients with COPD may not be completely free from symptoms or exacerbations even under optimized therapy; therefore, control in COPD does not mean cure or absence of symptoms, but rather reaching the best clinical status possible according to the level of disease severity. A control tool has been developed based on a cross sectional evaluation of the impact of the disease and a longitudinal evaluation of stability. Low impact is a disease status defined by at least 3 of the following: low levels of dyspnoea, absence of or white sputum, low use of rescue medication and self-declared walking time of more than 30 minutes a day, and stability is the absence of moderate or severe exacerbations in the previous 3 months. Control can also be defined by COPD Assessment Test (CAT) scores $\leqslant 10$ units for patients with FEV 1 in $50 \%$ and 16 for patients with $\mathrm{FEV}_{1}<50 \%$ and stability as a change in CAT $\leqslant 2$ units. Control of COPD is then defined as a status of low impact and stability. The control tool has been validated prospectively in several studies and has demonstrated to be sensitive to clinical changes and to have a good predictive value for poor outcomes. Clinical criteria are more reliable than CAT scores for the evaluation of control. The control tool is a quick and inexpensive method to evaluate clinical status and future risk of exacerbations that can be used at all levels of healthcare.

Key words: chronic obstructive pulmonary disease (COPD), control, COPD Assessment Test, outcomes.
\end{abstract}

For citation: Miravitlles M., Alcázar B., Soler-Cataluña J.J. The concept of control in chronic obstructive pulmonary disease: Development of the criteria and validation for use in clinical practice. Russian Pulmonology. 2020; 30 (2): 135-141 (in Russian). DOI: 10.18093/0869-0189-202030-2-135-141

Chronic obstructive pulmonary disease (COPD) is considered to be a syndrome with different endotypes and phenotypes [1]. This heterogeneity of the disease also implies difficulties in establishing a prognosis and identifying the best treatment strategy for each individual patient. In this context, personalization of treatment is very relevant for patients with COPD [2, 3].

The most cited international recommendations on the management of COPD are those of the Global Strategy for Obstructive Lung Disease (GOLD). These recommendations divide COPD patients into four subgroups according to the intensity of symptoms and frequency of exacerbations in order to initiate pharmacological treatment [4]. Similarly, for the continuation of treatment, step up or down decisions are based on the persistence of symptoms (i.e. dyspnoea) or exacerbations, or both. However, the last update of GOLD also introduced the use of eosinophil blood concentrations to help in the decision about when to use inhaled corticosteroids (ICS) as a first approach to a phenotypic treatment [4].

Other guidelines recommend directing pharmacological treatment according to the different phenotypes of COPD, particularly, emphysema, chronic bronchitis, frequent exacerbators and asthma-COPD overlap (ACO) [5] or using the eosinophilic inflammatory pattern to guide therapy [6].
Irrespective of the classification used, the criteria for stepping treatment up and down is not well defined in the current guidelines. The GOLD strategy recommends reassessing symptoms and exacerbations at every clinical visit but does not give any clue as to how to evaluate the efficacy of treatment [4]. The concept of control of COPD was developed with the objective to help clinicians in the decision to increase or decrease the intensity of treatment, both pharmacologically as well as non-pharmacologically. This concept of control has been well developed in asthma [7]; however, in COPD the characteristics of the disease have made this concept elusive [8,9]. Basically, COPD is a chronic disease and treatment may alleviate symptoms, reduce exacerbations and improve quality of life, but will not cure the disease or completely eliminate its manifestations [10]. Therefore, unlike asthma, control in COPD does not mean "cured" or totally asymptomatic, and some gold standard must be identified in order to classify a patient as controlled [11].

Defining control in COPD is hampered by the great heterogeneity of the disease. It is well known that patients with the same level of lung function impairment may have very different symptom burdens, or patients with the same health status may have different risks of exacerbations [12]. Therefore, the concept of control should incorporate the main objectives of the treatment of COPD: reduce symp- 
toms and risk of exacerbation, while also considering other important aspects of the disease that may impact the quality of life of patients and may be modified by treatment [13].

Over the last seven years there has been an initiative to develop the concept of control in COPD to help clinicians in the escalation and descalation of treatment $[14,15]$. The development of this concept required a first phase of identifying the relevant variables or criteria of control and establishing the cut-offs and a second phase of clinical validations in different populations. In this manuscript we describe the development of the idea of control in COPD and the results of the validation process. Finally, we give some recommendations as to how this concept can be used in routine clinical practice.

\section{The need for control in chronic obstructive pulmonary disease}

According to the Webster dictionary, one of the meanings of control is: "to reduce the incidence or severity of, especially to innocuous levels" [16]. This definition includes the concept of achieving the best possible health status of the patient. Unfortunately, in COPD, the main objective of treatment nowadays is not to cure, but rather to have the disease "under control" or with the lowest impact on the patient $[10,17]$.

Objective physiological measures of lung function and multicomponent indices are very helpful in evaluating the stage of the disease and establishing a prognosis [18], and the use of patient reported outcomes (PROs) helps to understand the impact of the disease on health-related quality of life, sleep quality and mood, among others [19]. However, these measures are not sensitive enough to guide treatment decisions.

In this context, it has been proposed that control in COPD should consist of two axes, which reflect the impact and stability of the condition [14, 15]. Impact is related to the manifestations of the disease and how the patients feel their disease at the time of medical consultation, and stability is related to changes of the clinical sta- tus of the patient over time, including the presence of exacerbations.

Control in COPD is a conceptual dimension requiring demonstration of both low impact and clinical stability of disease. The developers of the concept hypothesize that patients with controlled COPD will have better clinical outcomes (reduced frequency of exacerbations and mortality, and improved health-related quality of life), as well as a slower decline in lung function and reduced COPDrelated healthcare costs $[14,15]$.

Furthermore, control should be a tool easy to implement at all levels of patient care, from specialised clinics in teaching hospitals to primary care practices, and should not require expensive equipment. In other words, the concept of control must be a simple and inexpensive tool that can be used in routine clinical practice in primary care [13]. With such a tool it would be possible to reassess the impact and effectiveness of therapies at each clinical visit, as recommended by the GOLD strategy [4], and make informed decisions about stepping therapy up or down.

\section{Initial validation of the concept of control in chronic obstructive pulmonary disease}

It was clear from the beginning that criteria were needed to help define the current clinical situation of the patient and, at the same time, provide knowledge of the temporal evolution of the disease with easy identification of possible changes. On one hand, the current clinical situation of the patient is a cross-sectional and static assessment corresponding to a specific time, which will hereafter be referred to as "impact". However, the temporal evolution of this impact is a dynamic term which needs at least two observations over time and is framed within the concept of clinical stability. From the interaction of these two concepts of impact and stability a new dimension is derived, which we will denominate "control of COPD" (Figure 1) [14, 15].

The criteria for defining impact were identified based on the clinical experience of the authors, who selected only those that can be readily available at each clinical

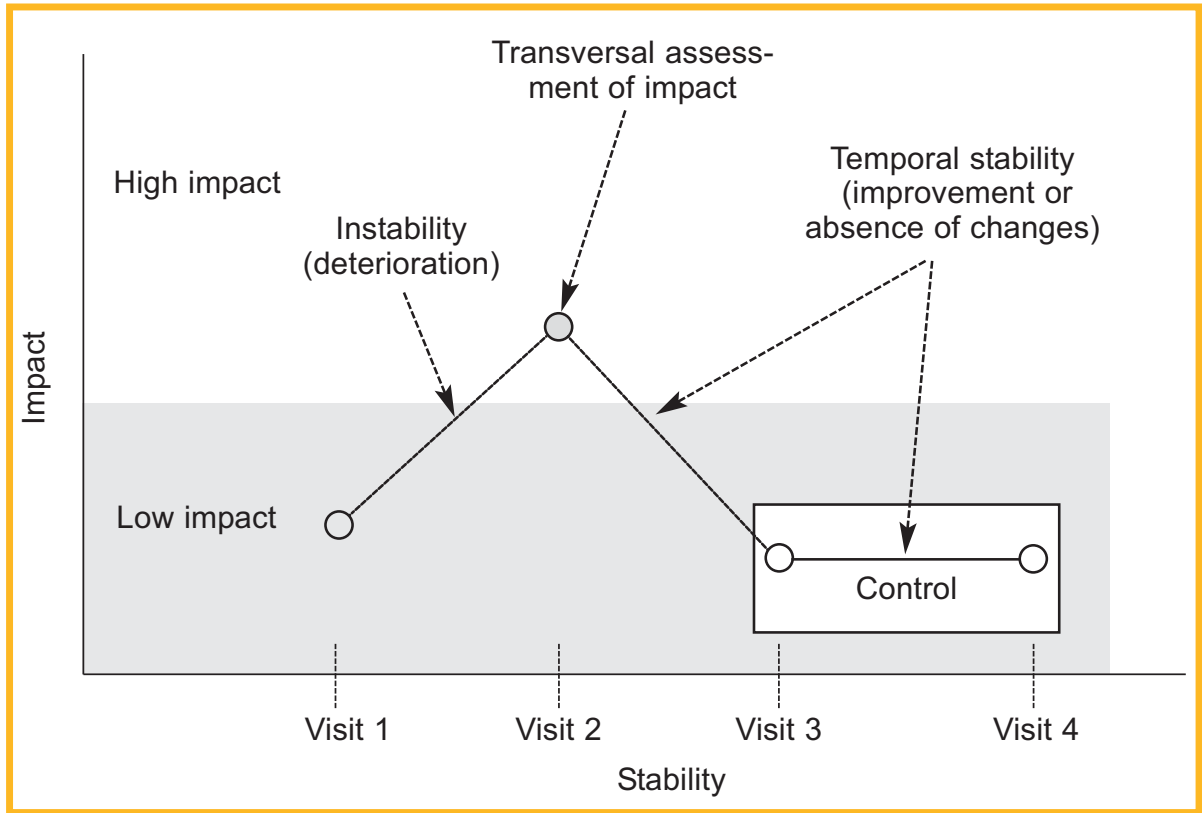

Figure 1. Representation of the concept of impact, stability and control in chronic obstructive pulmonary disease* Notes: Circles represent the transversal measurement of the clinical situation at different time points (impact); lines show the analysis of the changes (stability) and the shaded area marks the concept of control, understood as the desirable situation in which a condition of low clinical impact is maintained over a long period of time according to the severity of the disease; * - Reproduced with permission of the CERS, 2020 [14]. 


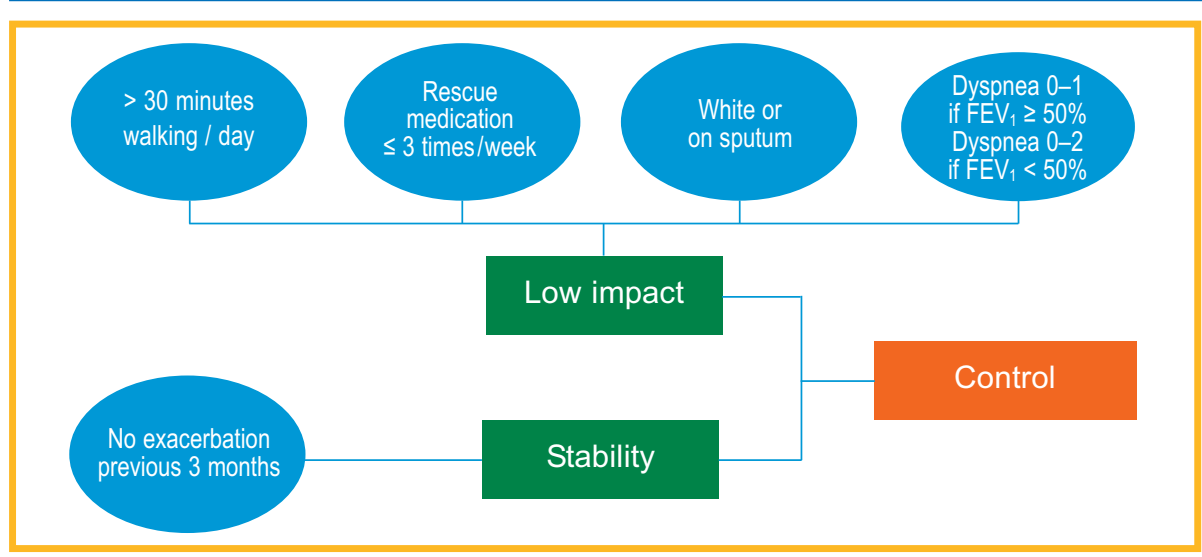

Figure 2. The control tool for determination of control status in control in chronic obstructive pulmonary disease

visit at any level of healthcare $[14,15]$. The candidate criteria were:

- A. Level of dyspnoea; which is considered one of the key objectives of treatment by the GOLD initiative [4] and is closely related to quality of life [20] and is even a prognostic factor for survival [21]. The modified Medical Research Council (mMRC) questonnaire is a validated dyspnoea scale that is easy to use in clinical practice [22].

- B. The presence of chronic sputum production defines chronic bronchitis and is a risk factor for frequent and severe exacerbations, accelerated decline in lung function and worse quality of life [23]. In addition, the presence of dark sputum in stable state is associated with the presence of pathogenic bacteria and indicates higher levels of inflammation and increased risk for exacerbations [24].

- C. Increased use of rescue medication is also a marker of poor prognosis, that indicates a worse quality of life and increased risk for exacerbations [25].

- D. Low levels of physical activity are associated with more symptoms, depression, and more frequent and severe exacerbations [26]. The self-declared minutes per day walking is an easy measure of physical activity related to quality of life and relevant outcomes in COPD [27].

Since patients with COPD may have a wide range of clinical severity, the threshold to define high impact may differ between different degrees of COPD severity. As an example, an mMRC dyspnoea score of 2 may be a good indicator or represent low impact in a very severe COPD patient but may indicate a high impact in a mild patient.

Stability is a dynamic concept that requires a window of observation time. This window is the time period between the usual follow-up clinical visits and may be of 3 , 6 or 12 months, according to the severity and clinical situation of the patient. In order to classify a patient as stable we decided that there should be a lack of exacerbations or clinical worsening during the previous three months.

Initially, we also wanted to test whether the use of a simple validated questionnaire could be used as a marker of control status [14, 15]. The COPD Assessment Test (CAT) is a widely used short symptoms questionnaire recommended by GOLD [28, 29], and several guidelines recommend it for assessing the need for treatment in COPD [4-6]. The hypothesis was that the CAT could be used as a measure of impact, and changes in CAT could also inform about stability, and the two together could establish the control status of the patient.

Finally, control of COPD was defined as maintenance of a situation of low impact over time adapted to the severity of the disease itself. Therefore, in order to establish a situation of optimal control of COPD the following criteria should be fulfilled (Figure 2):

- Low impact according to the baseline severity of the disease.

- Stability defined by the absence of significant clinical worsening of CAT scores or by the absence of exacerbations in the previous three months.

Patients fulfilling these criteria may be classified as controlled and the term "not controlled" should be reserved for the remaining cases.

The initial control criteria were tested in a group of 59 COPD patients in a single centre in Spain [15]. They were classified as mild or moderate to severe based on a Body mass index, Obstruction, Dyspnoea and Exacerbations (BODEx) index above or below 4 . Of these patients, $51 \%$ were classified as controlled, but only $25 \%$ of severe patients were controlled [15]. The same control criteria were retrospectively tested in a cohort of patients from the Optimum Patient Care Research Database (OPCRD) in the UK [30]. In this case, 2788 patients were classified as mild to moderate based on a BODEx index $\leqslant 4(90 \%)$ or severe with a BODEx index $>4(10 \%)$, and all the patients had at least 15 months of follow-up to evaluate the prognostic value of the control status at baseline. The results showed that only $4.5 \%$ of the mild-moderate patients fulfilled the criteria for control and none of the severe patients was classified as controlled using the clinical criteria. On the other hand $21.5 \%$ of mild-moderate and $8.3 \%$ of patients with severe COPD were classified as controlled by CAT criteria. Interestingly, control status, either by clinical criteria or by CAT scores, was significantly associated with a better prognosis, demonstrated by a significant delay in time to the first exacerbation [30].

Since the previous retrospective study included basically mild to moderate patients from primary care, we tested the prognostic value of the initial control criteria in severe COPD patients from the database of the SPARK study. The SPARK study was a 64-week, double-blind, parallel-group multicentre study which included patients with severe and very severe COPD with at least one moderate exacerbation in the previous 12 months. Patients were randomised to receive tiotropium $18 \mu \mathrm{g}$, glycopyrronium 
$50 \mu \mathrm{g}$ or a fixed-dose combination of indacaterol and glycopyrronium $110 / 50 \mu \mathrm{g}$ for 64 weeks, all once daily [31]. The SPARK study did not include the same variables used to define control, and therefore, we had to use proxis from the database, as described in the publication [32]. In this population of severe patients, $20 \%$ were classified as controlled by clinical criteria at baseline, and the analysis confirmed that patients classified as controlled at the beginning of the study had a prolonged period to the first moderate to severe exacerbation compared with uncontrolled patients. The hazard ratio (HR) was 0.58 for risk to moderate to severe exacerbations (95\% confidence interval $(\mathrm{CI}): 0.49$ to $0.69 ; p<0.001$ ) [32]. This study confirmed that the control criteria were probably too stringent and only achievable by a minority of patients, and that control status was a useful tool to predict future outcomes.

\section{Refining the criteria for control in chronic obstructive pulmonary disease}

The great majority of patients included in the previously described studies were stable and attended by physicians dedicated to COPD. It was therefore difficult to accept that only a small minority of these patients could be classified as controlled. This led to the idea that the original thresholds proposed for low impact could be too demanding and could induce overtreatment in a significant number of patients with COPD.

We used the database of the baseline data of the first international multicentre prospective control study to investigate the effect of modifying the thresholds of symptoms and CAT scores to define impact and control status in a population of 314 patients with COPD [33]. Similarly to the SPARK population, only $21 \%$ of the patients were classified as controlled, and the main reasons for not being controlled were the high degree of dyspnoea, a high CAT score or an exacerbation in the previous 3 months. Additionally, this study identified female sex, having chronic bronchitis and having frequent exacerbations in the previous year as independent factors significantly increasing the probability of being non controlled [33]. In this dataset, a change in the criteria to classify patients into moderate or severe was tested. Instead of a BODEx index $\geqslant 5$, we used a BODEx index $\geqslant 3$ to classify a severe patient with COPD. Nonetheless, this change did not significantly modify the distribution of patients in controlled and uncontrolled status [33]. From this analysis it was clear that the thresholds of the individual symptoms should be explored further, and this was performed in the next prospective study.

Soler-Cataluña et al. [34] evaluated a total of 265 patients with COPD over a period of one year. At the baseline visit, all variables included in the control concept were collected, including the CAT questionnaire. Data showed that all the criteria for control except physical activity and CAT scores were significantly and independently associated with the future risk of exacerbations. However, all the preselected variables were associated with relevant outcomes, such as quality of life and, therefore, all of these variables were kept in the definition of impact. Other important findings were that at least three of the four clinical criteria were required to classify a patient as low impact,
Table 1

Modified control criteria, with adjustment for severity according to the forced expiratory volume in the first second in percent predicted; $\%$

CLINICAL EVALUATION Criteria of control stratified by severity; FEV 1 (\%)

Low impact by clinical criteria

(at least three of the four criteria should be fulfilled)

\begin{tabular}{|c|c|c|}
\hline & $\mathrm{FEV}_{1} \geq 50 \%$ & $\mathrm{FEV}_{1}<50 \%$ \\
\hline - Dyspnoea (mMRC) & $0-1$ & $0-2$ \\
\hline - Rescue medication & \multicolumn{2}{|c|}{$\leq 3$ times / week } \\
\hline - Sputum colour & \multicolumn{2}{|c|}{ White or no sputum } \\
\hline - Physical activity & \multicolumn{2}{|c|}{$\geq 30 \mathrm{~min} /$ day } \\
\hline \multicolumn{3}{|c|}{ Clinical stability by clinical criteria } \\
\hline $\begin{array}{l}\text { Exacerbations in the } \\
\text { last } 3 \text { months }\end{array}$ & \multicolumn{2}{|c|}{ None } \\
\hline Control by clinical criteria & \multicolumn{2}{|c|}{ Low impact + Stability } \\
\hline EVALUATION BY CAT & \multicolumn{2}{|c|}{ Criteria of control stratified by severity; $\mathrm{FEV}_{1}(\%)$} \\
\hline \multicolumn{3}{|l|}{ Low impact by CAT } \\
\hline & $\mathrm{FEV}_{1} \geq 50 \%$ & $\mathrm{FEV}_{1}<50 \%$ \\
\hline - CAT & $0-10$ & $0-16$ \\
\hline \multicolumn{3}{|l|}{ Stability by CAT } \\
\hline - CAT changes & \multicolumn{2}{|c|}{$\leq 2$ points } \\
\hline Control by CAT & \multicolumn{2}{|c|}{ Low impact + Stability } \\
\hline
\end{tabular}

Notes: CAT, COPD Assessment Test; FEV percent predicted; mMRC, modified Medical Research Council dyspnoea scale.

and that the best cut-off to classify patients into two groups of severity was an $\mathrm{FEV}_{1}$ of $50 \%$ predicted. By classifying severity according to the $\mathrm{FEV}_{1}(\%)$ and using the new thresholds of low impact, almost $56 \%$ of patients could be classified as controlled by clinical criteria and $57 \%$ by CAT criteria [34].

These new percentages appeared to be more adequate to the clinical reality of patients with COPD in everyday practice, but they should be reliable predictors of outcomes if they were to be used in clinical practice. The new control criteria were tested during the one year follow-up, and patients uncontrolled at baseline had an increased risk of the composite event (exacerbation, hospitalisation or death), with a HR - 2.50 (95\% CI: 1.53 to 4.07; $p<0.001$ ) for control based on clinical criteria and also a significant, albeit lower, control based on CAT criteria with a HR - 1.79 (95\% CI: $1.11-2.90 ; p<0.001)$ [34]. These results confirmed that the new control criteria were easy to implement and more adequate for clinical practice with a very good prognostic value, being better for the clinical criteria compared to CAT (table 1).

\section{Prospective validation of the definitive control criteria}

The studies conducted initially demonstrated that control status identified a subgroup of patients that had better long-term outcomes in terms of reduced exacerbations and probably better survival. However, before the control tool could be extensively used in clinical practice to help in therapeutic decision making, more validations were needed.

Ideally, the degree of control should be:

- related to the clinical status of the disease; uncontrolled patients should have a worse quality of life, and losing control should be associated with worsening of other clinical parameters; 
- associated with different clinically relevant outcomes (greater control, better outcomes);

- sensitive to change in clinical status;

- able to be modified by the treatment in that the therapeutic objective involves seeking control for each level of basal severity.

A new series of studies were conducted in order to further validate the use of control status in clinical practice. A Spanish multicentre, observational study in 354 COPD patients aimed to investigate the sensitivity of the control tool to changes in clinical status by comparing changes in control over a 3-month period with changes in GOLD A-D categories and in risk level and clinical phenotype (non-exacerbator, asthma-COPD overlap, exacerbator with emphysema or with chronic bronchitis) [35], according to the Spanish guidelines of COPD [3, 5, 36]. At 3 months, the proportion of controlled patients was $50.3 \%$ by clinical criteria and $47.8 \%$ by CAT [35].

During the 3-month follow-up, the control status of $87(29.2 \%)$ patients changed as assessed by clinical variables and $85(28.5 \%)$ according to CAT. In contrast, the risk level only changed in $26(8.7 \%)$ patients $(p<0.001)$, $27(9.1 \%)$ experienced changes in their clinical phenotype $(p<0.001)$ and $59(19.8 \%)$ in the GOLD classification $(p=0.008)$ [35]. These results indicated that control status was more sensitive to changes in clinical status than the other usual severity markers used in guidelines [3, 4, 36]. Moreover, change in control status demonstrated to be clinically meaningful, because patients who showed an improvement in control status over 3 months had better CAT scores at the end of follow-up and, conversely, patients who changed control status from controlled at baseli- ne to uncontrolled at the end of follow-up experienced a significant impairment in CAT scores $(p<0.001$ for both comparisons) [35].

A prospective international multicentre study was conducted with the objective to further validate the long-term prognostic value of control status [37]. The characteristics of the patients recruited and their control status at baseline have been described in a previous section of this article [33]. The patients were followed for 18 months, and the main outcome was the difference in a composite outcome: exacerbations, hospitalisations or death, during follow-up between controlled and uncontrolled patients at baseline. A total of 307 patients with different levels of severity from 7 countries were evaluated, and 197 (65\%) were classified as controlled by clinical criteria. The proportion of controlled patients was $68.5 \%$ of mild/moderate and $59.3 \%$ of severe COPD patients using an $\mathrm{FEV}_{1}-50 \%$ as the cutoff. Regarding CAT, only $37.9 \%$ were classified as controlled; $41.5 \%$ among the mild/moderate and $34.5 \%$ of severe COPD patients. Patients classified as controlled at baseline had significantly fewer exacerbations during follow-up, and especially when classified as controlled by clinical criteria (mean of 1.1 versus 2.6 ; $p<0.001$ ). Differences were lower, although still significant, when using CAT criteria of control (1.1 mean exacerbations in controlled versus 1.9 in uncontrolled patients; $p=0.014$ ). However, only patients controlled by clinical criteria showed a significantly increased time to the first exacerbation compared to uncontrolled (median 93 days versus 274 days; $p<0.001$ ). Finally, control status measured with clinical criteria was a better predictor of combined event (area under the receiver operating characteristics (ROC)

Table 2

Main characteristics and results of control studies

\begin{tabular}{|c|c|c|c|c|}
\hline Reference & Design & Population & Main Results & Interpretation \\
\hline $\begin{array}{l}\text { J.J.Soler-Cataluña } \\
\text { et al., } 2014 \text { [15] }\end{array}$ & Prospective Unicentre & $\begin{array}{l}59 \text { patients, } \\
\text { FEV }_{1}(\%)=55 \%\end{array}$ & $\begin{array}{l}\text { Controlled: } 60 \% \text { of mild-moderate } \\
\text { and } 30 \% \text { of severe }\end{array}$ & $\begin{array}{l}\text { Control criteria are easy to implement } \\
\text { but must be refined }\end{array}$ \\
\hline $\begin{array}{l}\text { A.Nibber et al., } \\
2017[30]\end{array}$ & $\begin{array}{l}\text { Retrospective, database } \\
\text { study in UK }\end{array}$ & $\begin{array}{l}2788 \text { patients, } \\
\text { of whom } \\
277 \text { were severe }\end{array}$ & $\begin{array}{l}\text { Controlled: } 4.5 \% \text { of mild-moderate } \\
\text { and } 0 \% \text { of severe. Control status } \\
\text { predictive of exacerbations }\end{array}$ & $\begin{array}{l}\text { Control criteria too restrictive. Control } \\
\text { status is a good predictive tool }\end{array}$ \\
\hline $\begin{array}{l}\text { M.Miravitlles et al., } \\
2018 \text { [33] }\end{array}$ & $\begin{array}{l}\text { Cross-sectional analysis of } \\
\text { a prospective, international., } \\
\text { multicentre study }\end{array}$ & $\begin{array}{l}314 \text { patients from } \\
7 \text { countries, } \\
\text { FEV }_{1}(\%)=52 \%\end{array}$ & $\begin{array}{l}\text { Controlled } 21 \% \text { all mild to moderate. } \\
\text { Change in severity threshold did not } \\
\text { and new thresholds identified }\end{array}$ & $\begin{array}{l}\text { Initial control criteria should be refined, } \\
\text { and new thresholds identified }\end{array}$ \\
\hline $\begin{array}{l}\text { J.J.Soler-Cataluña } \\
\text { et al., } 2018 \text { [34] }\end{array}$ & $\begin{array}{l}\text { Prospective, two centres } \\
\text { in Spain }\end{array}$ & $\begin{array}{l}265 \text { patients, } \\
\operatorname{FEV}_{1}(\%)=58 \%\end{array}$ & $\begin{array}{l}\text { New control criteria identified and } \\
\text { validated prospectively }\end{array}$ & $\begin{array}{l}\text { The new control criteria are more ade- } \\
\text { quate for clinical use and have a good } \\
\text { predictive value. Clinical criteria are } \\
\text { more reliable than CAT criteria of control }\end{array}$ \\
\hline $\begin{array}{l}\text { M.Barrecheguren } \\
\text { et al., } 2020 \text { [32] }\end{array}$ & $\begin{array}{l}\text { Secondary analysis of } \\
\text { SPARK randomised } \\
\text { clinical trial }\end{array}$ & $\begin{array}{l}2044 \text { patients, } \\
\operatorname{FEV}_{1}(\%)=38 \%\end{array}$ & $\begin{array}{l}\text { Controlled patients had lower rate } \\
\text { of exacerbations ( } R R=0.56 \text { ) and } \\
\text { prolonged time to first exacerbation } \\
\text { (93 vs } 222 \text { days; } H R=0.58 \text { ) }\end{array}$ & $\begin{array}{l}\text { Control status was a good predictor of } \\
\text { exacerbations in a population of severe } \\
\text { COPD patients with frequent exacerba- } \\
\text { tions }\end{array}$ \\
\hline $\begin{array}{l}\text { M.Miravitlles et al., } \\
2020 \text { [37] }\end{array}$ & $\begin{array}{l}\text { Prospective, international., } \\
\text { multicentre, study }\end{array}$ & $\begin{array}{l}307 \text { patients, } \\
\operatorname{FEV}_{1}(\%)=52 \%\end{array}$ & $\begin{array}{l}\text { Controlled patients had lower rate of } \\
\text { exacerbations ( } 1.1 \text { vs } 2.6 \text { per year; } \\
p<0.001 \text { ) and prolonged time to } \\
\text { first exacerbation ( } 93 \text { vs } 274 \text { days; } \\
p<0.001 \text { ) }\end{array}$ & $\begin{array}{l}\text { The new control criteria provided } \\
\text { a very good predictive value for } \\
\text { exacerbations. Clinical criteria were } \\
\text { more reliable than CAT criteria } \\
\text { of control }\end{array}$ \\
\hline $\begin{array}{l}\text { J.J.Soler-Cataluña } \\
\text { et al., } 2020 \text { [35] }\end{array}$ & $\begin{array}{l}\text { Prospective, multicentre } \\
\text { study in Spain }\end{array}$ & $\begin{array}{l}354 \text { patients, } \\
\operatorname{FEV}_{1}(\%)=49 \%\end{array}$ & $\begin{array}{l}\text { During a 3-month period } 29 \% \text { of patients } \\
\text { changed control status, but only } 9 \% \\
\text { changed level of risk, } 9 \% \text { phenotype } \\
\text { and } 19 \% \text { GOLD A-D. Changes in control } \\
\text { over } 3 \text { months resulted in significant } \\
\text { changes in CAT scores }\end{array}$ & $\begin{array}{l}\text { Control status is more sensitive to clinical } \\
\text { changes than changes in phenotype, level } \\
\text { of risk of GOLD A-D. Changes in control } \\
\text { over } 3 \text { months reflect changes in quality } \\
\text { of life }\end{array}$ \\
\hline
\end{tabular}

Notes. FEV 1 , forced expiratory volume in one second; UK, United Kingdom; CAT, COPD Assessment Test; RR, Risk Ratio; HR, Hazard Ratio; GOLD, Global strategy for Obstructive Lung Disease. 
curve (AUC) - 0.67) compared with control status measured by CAT criteria (AUC - 0.57) [37]. These results confirmed that the newly selected control criteria were more adequate for clinical practice than the old criteria, because they identify around 50 to $60 \%$ of patients managed by specialised clinics as controlled and have a very good prognostic value for exacerbations. Another consistent result is that the clinical criteria of control perform better than the CAT criteria to predict poor outcomes. A summary of the different studies conducted to validate the control tool is presented in table 2 .

\section{The use of control in clinical practice}

Management of COPD according to GOLD is based on symptoms, basically dyspnoea and risk of exacerbations [4, 38]. The Spanish guidelines include the level of risk that also depends on the degree of lung function impairment [5]. However, there are no clear rules of evaluation of success and continuation of treatment; in other words, when and how treatment must be stepped up or down [39]. In this context, control status can be a simple tool that can be used at any healthcare level, because all the variables required can be obtained at each clinical visit without any costly diagnostic procedure.

It is important to consider that control status does not provide any specific diagnosis; a patient may be uncontrolled for a variety of reasons. Uncontrolled status is only an alert to take action but does not tell us what action to take. However, the control tool can be an excellent reminder to the clinician about the questions that COPD patients must be asked at each clinical visit and provide a simple prognostic tool.

The increased risk associated with the uncontrolled status justifies the use of control evaluation as a warning sign to foster more careful evaluation of the patients and the adoption of therapeutic measures according to the results of these investigations.

\section{Conclusion}

Control in COPD is a concept related to achieving the best clinical status possible according to the level of severity of the disease. The control tool developed is composed of a cross sectional evaluation, clinical impact and a longitudinal component, that is, clinical stability, and has demonstrated the ability to classify patients with different levels of risk of future outcomes. In addition, control status is more sensitive to clinical changes than phenotypes or the A-D GOLD classification. The variables required for control evaluation - level of dyspnoea, sputum, use of rescue medication, self-declared daily time walking and previous exacerbations - are easy to obtain at each clinical visit at any level of healthcare. Therefore, control status is ready for use in clinical practice to complement current COPD management guidelines and help in the decision to step therapy up or down to improve symptoms and reduce future risks in patients with COPD.

\section{Conflicts of interest}

Marc Miravitlles has received speaker fees from AstraZeneca, Boehringer Ingelheim, Chiesi, Cipla, Menarini, Rovi, Bial., Sandoz, Zambon, CSL Behring, Grifols and Novartis, consulting fees from
AstraZeneca, Boehringer Ingelheim, Chiesi, GlaxoSmithKline, Bial., Gebro Pharma, Kamada, CSL Behring, Laboratorios Esteve, Ferrer, Mereo Biopharma, Verona Pharma, TEVA, Spin Therapeutics, pH Pharma, Novartis, Sanofi and Grifols and research grants from GlaxoSmithKline and Grifols. Bernardino Alcázar declares to have received fees in the last 3 years for giving conferences, scientific advice, participation in clinical studies or writing publications for (alphabetical order): AstraZeneca, Boehringer Ingelheim, Chiesi, FAES, Ferrer, GlaxoSmithKline, Menarini, Novartis, Rovi.

Juan José Soler-Cataluña has received speaker fees from AstraZeneca, Bial., Boehringer Ingelheim, Chiesi, Esteve, Ferrer, GSK, Menarini, Mundipharma, Novartis, Rovi, and consulting fees from AstraZeneca, Boehringer Ingelheim, Chiesi, GSK, Mundipharma and Novartis.

\section{References}

1. Koblizek V., Milenkovic B., Barczyk A. et al. Phenotypes of COPD patients with a smoking history in Central and Eastern Europe: the POPE study. Eur. Respir. J. 2017; 49 (5): 1601446. DOI: 10.1183/13993003.01446-2016.

2. Calle Rubio M., Rodríguez Hermosa J.L., Soler-Cataluña J.J. et al. Medical care according to risk level and adaptation to Spanish COPD guidelines (GesEPOC): the Epoconsul study. Arch. Bronconeumol. 2018; 54 (5): 270-279. DOI: 10.1016/j.arbres.2017.11.015 (in English, Spanish).

3. Erro Iribarren M., Alonso Pérez T., Soriano J.B., Ancochea Bermúdez J. Adjusting the level of intervention in patients with chronic obstructive pulmonary disease according to the risk stratification proposed by the Spanish COPD guidelines (GesEPOC) version 2017. Arch. Bronconeumol. 2020; 56 (3): 183-185 DOI: 10.1016/j.arbres.2019.09.016 (in English, Spanish).

4. Singh D., Agusti A., Anzueto A. et al. Global Strategy for the Diagnosis, Management, and Prevention of Chronic Obstructive Lung Disease: the GOLD science committee report 2019. Eur. Respir. J. 2019; 53 (5): 1900164. DOI: 10.1183/13993003.00164-2019.

5. Miravitlles M., Soler-Cataluña J.J., Calle M. et al. Spanish guidelines for Management of chronic obstructive lung disease (GesEPOC) 2017: Pharmacological treatment of stable phase. Arch. Bronconeumol. 2017; 53 (6): 324-335. DOI: 10.1016/j.arbres.2017.03.018 (in English, Spanish).

6. Aisanov Z., Avdeev S., Arkhipov V. et al. Russian guidelines for the management of COPD: Algorithm of pharmacologic treatment. Int. J. Chron. Obstruct. Pulmon. Dis. 2018; 13: 183-187. DOI: 10.2147/COPD.S153770.

7. Thomas M., Kay S., Pike J. et al. Asthma Control Test (ACT) as a predictor of GINA guideline-defined asthma control: analysis of a multinational cross-sectional survey. Prim. Care Resp. J. 2009; 18 (1): 41-49. DOI: 10.4104/pcrj. 2009.00010.

8. Duarte Araújo A., Hespanhol V., Correia-de-Sousa J. Is COPD control a useful concept? Assessing treatment success by evaluating COPD-related health status. Arch. Bronconeumol. 2017; 53 (9): 530-531. DOI: 10.1016/j.arbres. 2016.11.024 (in English, Spanish).

9. Guimarães M., Bugalho A., Oliveira A.S. et al. COPD control: Can a consensus be found? Rev. Port. Pneumol. 2016; 22 (3): 167-176. DOI: 10.1016/j.rppnen.2016.01.004.

10. Monteagudo M., Rodríguez-Blanco T., Llagostera M. et al. Factors associated with changes in quality of life of COPD patients: a prospective study in primary care. Respir. Med. 2013; 107 (10): 1589-1597. DOI: 10.1016/j.rmed.2013.05.009.

11. Carter R.I., Stockley R.A. Disease "activity", "severity" and "impact": interrelationships in COPD; is a measure of disease "activity" the Holy Grail for COPD, or a variable impossible to quantify? COPD. 2014; 11 (4): 363-367. DOI: 10.3109/15412555.2013.808616. 
12. Agusti A., Calverley P.M., Celli B. et al. Evaluation of COPD Longitudinally to Identify Predictive Surrogate Endpoints (ECLIPSE) investigators. Characterisation of COPD heterogeneity in the ECLIPSE cohort. Respir. Res. 2010; 11: 122.

13. Soler-Cataluña J.J., Alcázar B., Miravitlles M. Clinical control in COPD: A new therapeutic objective? Arch. Bronconeumol. 2020; 56 (2): 68-69. DOI: 10.1016/j.arbr. 2019.06.011.

14. Soler-Cataluña J.J., Alcazar-Navarrete B., Miravitlles M. The concept of control in COPD: a new proposal for optimising therapy. Eur. Respir. J. 2014; 44 (4): 1072-1075. DOI: $10.1183 / 09031936.00064414$.

15. Soler-Cataluña J.J., Alcazar-Navarrete B., Miravitlles M. The concept of control of COPD in clinical practice. Int. J. Chron. Obstruct. Pulmon. Dis. 2014; 9: 1397-1405. DOI: 10. 2147/COPD.S71370.

16. Merriam-Webster Dictionary. Available at: https://www.merriam-webster.com/dictionary/control?src $=$ search-dict-box [Accessed: April 17, 2020].

17. Miravitlles M., Ribera A. Understanding the impact of symptoms on the burden of COPD. Respir. Res. 2017; 18 (1): 67. DOI: 10.1186/s12931-017-0548-3.

18. García-Río F., Soriano J.B., Miravitlles M. et al. Frequency of multi-dimensional COPD indices and relation with disease activity markers. COPD. 2013; 10 (4): 436-443. DOI:10. 3109/15412555.2012.761959.

19. Jones P.J., Miravitlles M., van der Molen T., Kulich K. Beyond $\mathrm{FEV}_{1}$ in COPD: a review of patient-reported outcomes and their measurement using a new generation of instruments. Int. J. Chron. Obstruct. Pulmon. Dis. 2012; 7: 697709. DOI: 10.2147/COPD.S32675.

20. Hanania N.A., O'Donnell D.E. Activity-related dyspnea in chronic obstructive pulmonary disease: physical and psychological consequences, unmet needs, and future directions. Int. J. Chron. Obstruct. Pulmon. Dis. 2019; 14: 1127-1138. DOI: $10.2147 /$ COPD.S188141.

21. Nishimura K., Izumi T., Tsukino M., Oga T. Dyspnea is a better predictor of 5-year survival than airway obstruction in patients with COPD. Chest. 2002; 121 (5): 1434-1440. DOI: $10.1378 /$ chest.121.5.1434.

22. Bestall J.C., Paul E.A., Garrod R. et al. Usefulness of the Medical Research Council (MRC) dyspnoea scale as a measure of disability in patients with chronic obstructive pulmonary disease. Thorax. 1999; 54 (7): 581-586. DOI: 10.1136/ thx.54.7.581.

23. Miravitlles M. Cough and sputum production as risk factors for poor outcomes in patients with COPD. Respir. Med. 2011; 105 (8): 1118-1128. DOI: 10.1016/j.rmed.2011.02.003.

24. Miravitlles M., Marin A., Monsó E. et al. Colour of sputum is a marker of bacterial colonization in chronic obstructive pulmonary disease. Respir. Res. 2010; 11 (1): 58. DOI: 10. 1186/1465-9921-11-58.

25. Jenkins C.R., Postma D.S., Anzueto A.R. et al. Reliever salbutamol use as a measure of exacerbation risk in chronic obstructive pulmonary disease. BMC Pulm. Med. 2015; 15: 97. DOI: $10.1186 / \mathrm{s} 12890-015-0077-0$.

26. Ramon M.A., Ter Riet G., Carsin A.E. et al. The dyspnoeainactivity vicious circle in COPD: development and external validation of a conceptual model. Eur. Respir. J. 2018; 52 (3): 1800079. DOI: 10.1183/13993003.00079-2018.

27. Ramon M.A., Esquinas C., Barrecheguren M. et al. Selfreported daily walking time in COPD: relationship with relevant clinical and funcional characteristics. Int. J. Chron. Obstruct. Pulmon. Dis. 2017; 12: 1173-1181. DOI: 10.2147/ COPD.S128234.

28. Jones P.W., Harding G., Berry P. et al. Development and first validation of the COPD Assessment Test. Eur. Respir. J. 2009; 34 (3): 648-654. DOI: 10.1183/09031936.00102509.

29. Miravitlles M., Koblizek V., Esquinas C. et al. Determinants of CAT (COPD Assessment Test) scores in a population of patients with COPD in Central and Eastern Europe: The POPE study. Respir. Med. 2019; 150: 141-148. DOI: 10. 1016/j.rmed.2019.03.007.

30. Nibber A., Chisholm A., Soler-Cataluña J.J. et al. Validating the concept of COPD control: a real-world cohort study from the United Kingdom. COPD. 2017; 14 (5): 504-512. DOI: $10.1080 / 15412555.2017 .1350154$.

31. Wedzicha J.A., Decramer M., Ficker J.H. et al. Analysis of chronic obstructive pulmonary disease exacerbations with the dual bronchodilator QVA149 compared with glycopyrronium and tiotropium (SPARK): a randomised, doubleblind, parallel-group study. Lancet Respir. Med. 2013; 1 (3): 199-209. DOI: 10.1016/S2213-2600(13)70052-3.

32. Barrecheguren M., Kostikas K., Mezzi K. et al. COPD clinical control as a predictor of future exacerbations: concept validation in the SPARK study population. Thorax. 2020; 75 (4): 351-353. DOI: 10.1136/thoraxjnl-2018-212752.

33. Miravitlles M., Sliwinski P., Rhee C.K. et al. Evaluation criteria for clinical control in a prospective, international, multicenter study of patients with COPD. Respir. Med. 2018; 136: 8-14. DOI: 10.1016/j.rmed.2018.01.019.

34. Soler-Cataluña J.J., Marzo M., Catalán P. et al. Validation of clinical control in COPD as a new tool for optimizing treatment. Int. J. Chron. Obstruct. Pulmon. Dis. 2018; 13: 3719-3731. DOI: 10.2147/COPD.S178149.

35. Soler-Cataluña J.J., Alcazar B., Marzo M. et al. Evaluation of changes in control status in COPD: An opportunity for early intervention. Chest. 2020; 157 (5): 1138-1146. DOI: 10.1016/j.chest.2019.11.004.

36. Cabrera López C., Casanova Macario C., Marín Trigo J.M. et al. Prognostic validation using GesEPOC 2017 Severity Criteria. Arch. Bronconeumol. 2019; 55 (8): 409-413. DOI: 10.1016/j.arbres.2018.12.002 (in English, Spanish).

37. Miravitlles M., Sliwinski P., Rhee C.K. et al. Predictive value of control of COPD for risk of exacerbations: An international, prospective study. Respirology. 2020. Apr. 6. DOI: 10.1111/resp.13811. [Epub ahead of print].

38. Miravitlles M., Roche N., Cardoso J. et al. Chronic obstructive pulmonary disease guidelines in Europe: a look into the future. Respir. Res. 2018; 19: 11. DOI: 10.1186/s12931-0180715-1.

39. Alcázar Navarrete B., Ancochea Bermúdez J., García-Río F. et al. Patients with chronic obstructive pulmonary disease exacerbations: Recommendations for diagnosis, treatment and care. Arch. Bronconeumol. 2019; 55 (9): 478-487. DOI: 10.1016/j.arbr.2019.02.011 (in English, Spanish).

Received: May 01, 2020 